
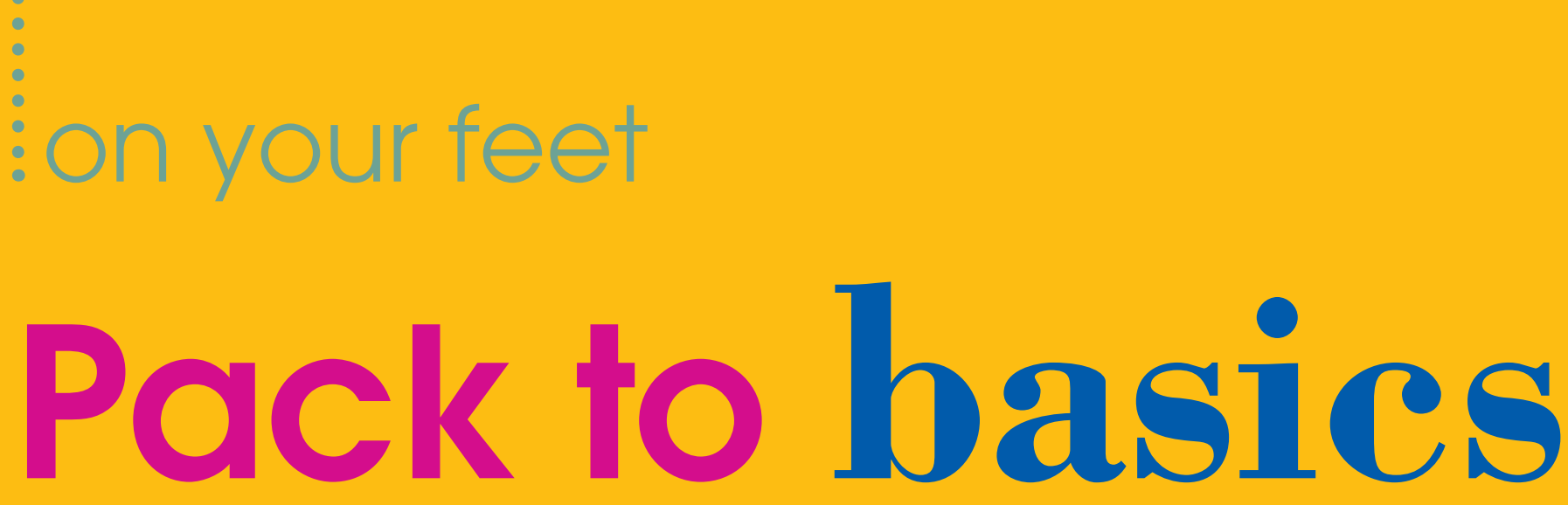

Hooray, the holiday season is just around the corner after what seems like an eternity. Kate Maynard is on hand to create a stress-free you with some essential tips to minimising your holiday wardrobe.

must confess to feeling rather smug when, upon departure to Majorca last year, my suitcase weighed barely $12 \mathrm{~kg}$ whereas my two friends' cases each tipped the scales at over twice that - one of them almost warranting a 'heavy' sticker. When we arrived at our tiny apartment, I popped my swiftly emptied case onto the top of the wardrobe, whereas my friends' cases spilled numerous bags, shoes, leaky bottles of shampoo and enough clothes for a six-month break, all over the floor. We were only there for a week!

It probably isn't the main thing you're thinking about when planning a holiday, but a bit of nifty packing goes a long way. If you're co-ordinating partner, kids, travel documents and several different forms of transport, the last thing you want to be doing is lugging a bulging case behind you, or paying excess luggage charges. The following tips should help you on your way.

\section{Hand luggage}

Put aside everything that needs to go in hand luggage; passports, tickets, money, travellers' cheques, currency, driving licence (in case you rent a car), in addition to any valuables like jewellery. It's a good idea to make a note of the number you can ring if your credit card goes missing or is stolen and leave it with someone you can contact easily.

If you're going self-catering then it's a good idea to take a tin opener, corkscrew and matches, but be conscious of the strict security at airports. The following are not allowed in hand luggage; knives, razors, scissors, nail clippers, sports equipment, aerosols including deodorant and insect repellent, or even knitting needles.

Decide how many outfits you really need, lay everything out on the bed and if there are more than two outfits for each day, you know you need to put some back. Select items which you can mix and match. Your favourite dress could be made into more than one outfit by varying your accessories.

Check the weather forecast and decide whether you really need a selection of cardigans and pashminas, or whether one light jacket will do - perhaps the one you're travelling in. Be conscious of the local customs at your holiday destination, for example, if you're heading to Egypt or Turkey, shorts and vest tops might be inappropriate or attract unwanted attention. A long-sleeved shirt or kaftan is also useful to cover up in the midday sun.

Rolling up tops and other soft clothing helps minimise creasing and they can then be cushioned around other items to make the most of space. Put shoes at the bottom of your case, close to the edge, and make sure the things you will need when you first arrive are near the top.

Pack enough underwear for the duration of your trip so you don't have to bother with washing. It can be wedged into the corners of your suitcase or inside shoes, and put one pair in your hand luggage just in case your luggage goes astray.

\section{Miniatures and mose uitioes}

Almost every lotion and potion is now widely available in miniature size, which is another great space-saver. Make sure you fasten them all into a washbag or plastic bag, and if possible, zip them into the separate compartment in your suitcase. Now is a good time to go through your makeup bag and throw away anything that looks like it's been there more than three months.

It might seem like common sense, but you'll kick yourself if you forget any of these little gems: lip balm, sunglasses, address book, mobile phone charger, camera, spare batteries, insect repellent, antihistamines, needle and thread, plasters, pain killers, high factor sun cream and aftersun. Don't expect to be able to buy familiar brands of toiletries while you're away, it's best to take them with you.

Leave enough space in your suitcase for anything you buy when you're away at markets

thin

\title{
$\mathbf{3 6}$ summer 06 vital
}

